\title{
Synthesis, impedance and dielectric properties of $\mathrm{LaBi}_{5} \mathrm{Fe}_{2} \mathrm{Ti}_{3} \mathrm{O}_{18}$
}

\author{
N V PRASAD, G PRASAD, T BHIMASANKARAM, S V SURYANARAYANA and \\ G S KUMAR* \\ Department of Physics, Osmania University, Hyderabad 500 007, India
}

MS received 10 January 2001; revised 20 June 2001

\begin{abstract}
The compound, $\mathrm{LaBi}_{5} \mathrm{Fe}_{2} \mathrm{Ti}_{3} \mathrm{O}_{18}$, is a five-layered material belonging to the family of bismuth layered structure ferroelectromagnetics. D.c. and a.c. conductivity measurements were performed on the samples. Dielectric measurements were also performed on these samples. Combined impedance and modulus plots were used as tools to analyse the sample behaviour as a function of frequency. Cole-Cole plots showed non-Debye relaxation.
\end{abstract}

Keywords. Bismuth layered structure ferroelectromagnetic (BLSFEM); relaxor ferroelectric; Debye relaxations; pyroelectric.

\section{Introduction}

Fifty years ago Aurivillius (1949, 1950) discovered a family of oxides with composition $\mathrm{Bi}_{2} \mathrm{O}_{2 n-1} \mathrm{R}_{n} \mathrm{O}_{3 n+1}$ where, $n=1,2,3,4,5$ represented the number of layers. The cubo-octahedral $\mathrm{M}$ site accepts $\mathrm{Bi}$ and several di/tri valent ions, while the smaller $\mathrm{Ti}$ ion goes into the octahedral $\mathrm{R}$ sites. The structure consists of $\left(\mathrm{Bi}_{2} \mathrm{O}_{2}\right)^{2+}$ layers interleaved with perovskite like $\left(\mathrm{M}_{n-1} \mathrm{R}_{n} \mathrm{O}_{3 n+1}\right)$ layers. The plate-like crystal structure of these compounds leads to highly anisotropic ferroelectric properties (Subba Rao 1962; Fregoso 1997; Takenaka and Sakata 1980, 1983, 1984). Partial replacement of Ti by Fe in these layer-compounds make them ferroelectromagnetic (FEM) materials, which show magnetoelectric (ME) effect. Therefore, these materials can also be referred to as bismuth layered structure ferroelectromagnetic (BLSFEM) materials.

In these BLSFEM materials, both ferroelectric and magnetic orders were observed. Among the other layer compounds so far mentioned above, the five-layered compound, $\mathrm{Bi}_{6} \mathrm{Fe}_{2} \mathrm{Ti}_{3} \mathrm{O}_{18}$ (BFT), showed higher transition temperature (Ismailzade et al 1971; Singh 1996). In order to reduce the transition temperature and to enhance the magnetoelectric output, both magnetic and non-magnetic rare earth ions were substituted in place of $\mathrm{Bi}$ in BFT compound (Prasad and Kumar 2000). Deverin (1978) reported the ferroelectric transition temperatures of $\mathrm{Bi}_{6} \mathrm{Fe}_{2} \mathrm{Ti}_{3} \mathrm{O}_{18}$ (BFT) at 752 and $898^{\circ} \mathrm{C}$. Singh (1996) confirmed the same results. Ismailzade et al (1971) and James et al (1998) also reported single-phase transition in case of $\mathrm{LaBi}_{4} \mathrm{FeTi}_{3} \mathrm{O}_{15}$ compound. These peaks were found to be broad and of diffusive type.

*Author for correspondence
The impedance analysis has been widely used to study the dielectric behaviour of the crystalline and polycrystalline ceramic materials. In general, the dielectric properties of ferroelectromagnetic materials arise due to intra-grain, inter-grain and other electrode effects. The motion of charges could take place by charge displacement, dipole reorientation, space charge formation etc (Von Hipple 1954; Macdonald 1987). In order to understand the electrical properties of a given sample grain, grain boundary and electrode contributions must be separated out. Complex impedance analysis has emerged as a very powerful tool for separating out these contributions. Similar analyses on different types of ferroelectromagnetic compounds have been reported earlier (James 1997; Mahesh Kumar 1998; Prasad et al 1998, 2000).

The inter relationship of impedance $\left(Z^{*}\right)$, admittance $\left(Y^{*}\right)$, modulus $\left(M^{*}\right)$ and dielectric permittivity $\left(\varepsilon^{*}\right)$, which are complex in nature, are given below.

$$
\begin{aligned}
& M^{*}=j \omega C_{0} Z^{*}, \\
& \varepsilon^{*}=\left(M^{*}\right)^{-1}, \\
& Y^{*}=\left(Z^{*}\right)^{-1}, \\
& Y^{*}=j \omega C_{0} \varepsilon^{*} .
\end{aligned}
$$

To elicit more information about the mechanism of electrical transport in this compound, impedance and dielectric measurements were carried out on this sample at different frequencies and different temperatures on $\mathrm{La}$ substituted BFT $\left(\mathrm{LaBi}_{5} \mathrm{Fe}_{2} \mathrm{Ti}_{3} \mathrm{O}_{18}\right)$ compound.

\section{Experimental}

$\mathrm{LaBi}_{5} \mathrm{Fe}_{2} \mathrm{Ti}_{3} \mathrm{O}_{18}$ (LBFT) was prepared by normal powder ceramic method. To synthesize the LBFT sample, AR 
grade of $\mathrm{La}_{2} \mathrm{O}_{3}, \mathrm{Bi}_{2} \mathrm{O}_{3}, \mathrm{TiO}_{2}$ and $\mathrm{Fe}_{2} \mathrm{O}_{3}$ were taken in stoichiometric ratios. The reactants were mixed thoroughly, using agate mortar and pestle. The mixture was pre-sintered at $850^{\circ} \mathrm{C}$ for $2 \mathrm{~h}$. Requisite amount of polyvinyl alcohol was added as a binder before making into final stage of pellets. Circular disc shaped pellets were made by applying uniaxial stress of $8 \mathrm{MPa}$. The products were subsequently heated up to $950^{\circ} \mathrm{C}$ for $4 \mathrm{~h}$.

$\mathrm{X}$-ray diffraction data was acquired on the powder sample of $\mathrm{LaBi}_{5} \mathrm{Fe}_{2} \mathrm{Ti}_{3} \mathrm{O}_{18}$ (LBFT) using $\mathrm{CuK}_{\alpha}$ radiation. Data was collected over the range $20^{\circ}-60^{\circ}$, with a scan rate of $2 \% \mathrm{~min}$.

Electrical impedance $(Z)$ and the phase angle $(\theta)$ were measured using impedance analyser HP 4192A as a function of frequency (in the range $1 \mathrm{kHz}-1 \mathrm{MHz}$ ) at different temperatures $\left(30-600^{\circ} \mathrm{C}\right)$. Capacitance and loss data were obtained at $10 \mathrm{kHz}$, using HP 4192A-impedance analyser.

Pyroelectric properties are the inherent properties of ferroelectric materials, since they exhibit spontaneous polarization. Pyroelectric current was measured continuously with increasing temperature, at a uniform rate of $4^{\circ} / \mathrm{min}$, using $610 \mathrm{C}$ Keithley electrometer. Prior to the measurement the samples were poled electrically at $30 \mathrm{kV} / \mathrm{cm}$ field at $140^{\circ} \mathrm{C}$.

D.c. conductivity measurements were made by using conventional two-probe method, using 610C Keithley electrometer. A.c. conductivity data was obtained from impedance data, using the relation $\sigma_{\text {a.c. }}=Y^{\prime}(t / A)$, where $Y^{\prime}$ is the real part of admittance. $t$ and $A$ are the thickness and area of the samples, respectively.

\section{Results and discussion}

The X-ray patterns were indexed on the basis of BFT compound. The maximum intensity was observed at $\sim 30^{\circ}$ of $2 \theta$ value, corresponding to $(1,1,11)$ reflection, which was also observed in the parent compound. The XRD pattern is shown in figure 1. This compound is found to be a single-phase material, since no extra peaks were observed nor peaks due to constituent oxides or $\mathrm{LaFeO}_{3}$ could be traced. The lattice parameters, orthorhombic distortion $(b / a)$, inter layer distance $(c / a)$ and density values are given in table 1 .

Figure 2 shows a mixture of both needle-like and platelike structures. The average size of the plate is found to be roughly $3 \mu \mathrm{m}$.

Figures $3 \mathrm{a}$ and $\mathrm{b}$ show imaginary parts of impedance $\left(Z^{\prime \prime}\right)$ and modulus $\left(M^{\prime \prime}\right)$ vs frequency plots. With the increase in frequency, $Z^{\prime \prime}$ values are found to initially increase and show peaks at $300^{\circ} \mathrm{C}$ and then decrease. However, in the entire temperature range of measurement, $Z^{\prime \prime}$ peaks are found to shift towards higher frequencies and peak height decreases with the increase in temperature.

In the case of $M^{\prime \prime}$, peaks are found to shift to higher frequency side with the increase of temperature. It is also observed that with the increase in temperature, $Z^{\prime \prime}$ and $M^{\prime \prime}$ peaks are found to come closer and at still higher temperatures $\left(>540^{\circ} \mathrm{C}\right)$ they may occur at the same frequency.

The imaginary part of impedance $\left(Z^{\prime \prime}\right)$ vs real part of impedance $\left(Z^{\prime}\right)$ is plotted over a wide frequency range

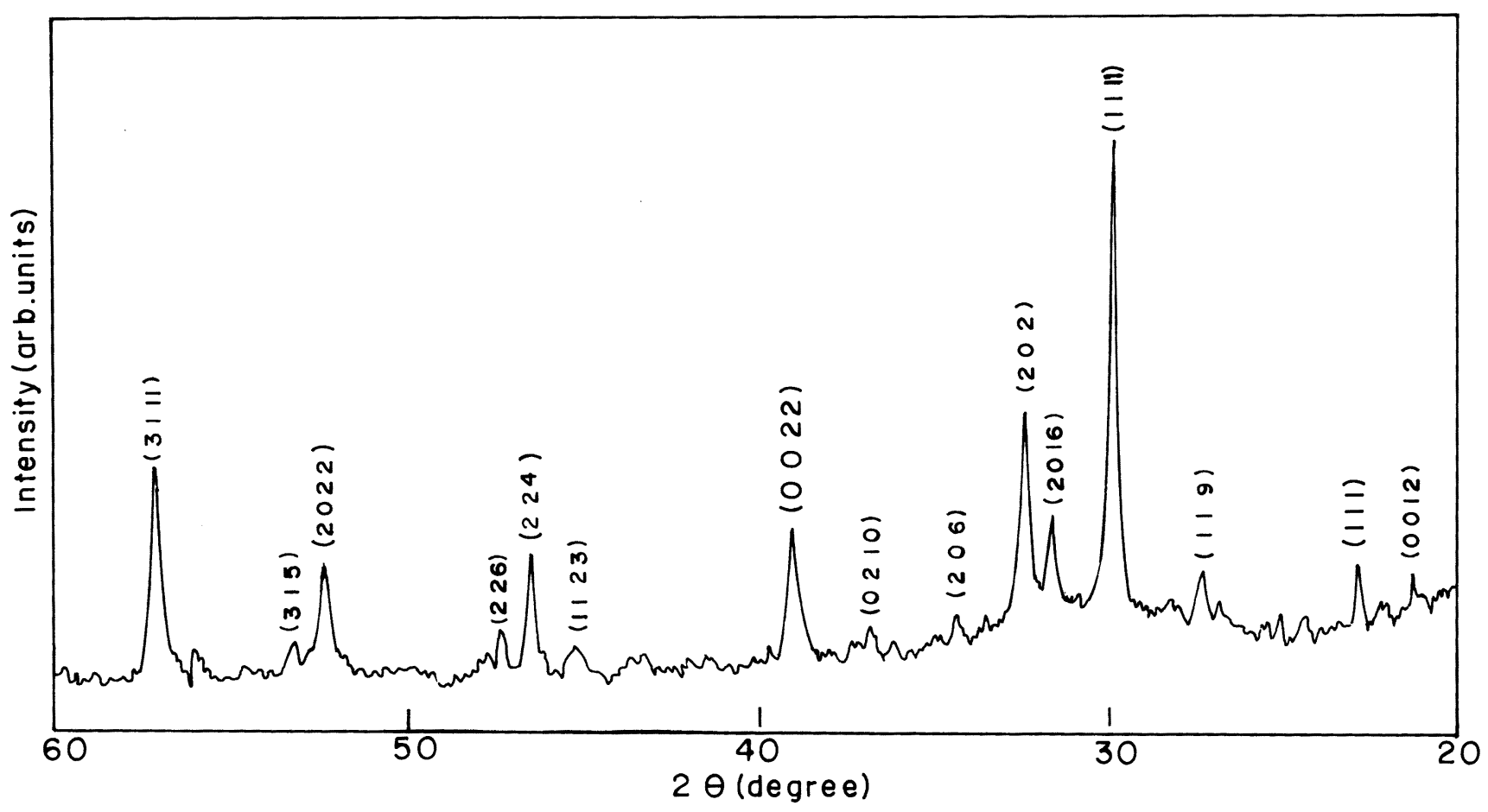

Figure 1. X-ray diffractogram of LBFT. 
$(1 \mathrm{kHz}-1 \mathrm{MHz})$ at different temperatures and is shown in figures $4 \mathrm{a}$ and $\mathrm{b}$. From the plots, it is seen that in general there are two semi circles, but at lower temperatures the second semi circle could not be traced and hence grain and grain boundary effects could not be separated. At higher temperatures $\left(>440^{\circ} \mathrm{C}\right)$ both the semi circles could be obtained separately, with different values of resistance for grain and grain boundary. A third semi circle could also be seen at $460^{\circ} \mathrm{C}$, which could be due to electrode effect. However, at lower temperatures, modulus plots (complementary plots of impedance plots, $M^{\prime \prime}$ vs $M^{\prime}$ ) were used to obtain grain and grain boundary resistance and relaxation values (figures not presented).

Grain and grain boundary resistance $r_{\mathrm{g}}, r_{\mathrm{gb}}$ respectively are obtained from the complex impedance and modulus plots (Cole and Cole 1941) depending upon the temperature. The plots between resistance $\left(r_{\mathrm{g}}, r_{\mathrm{gb}}\right)$, relaxation time $\left(\varepsilon_{\mathrm{g}}, \varepsilon_{\mathrm{gb}}\right)$ and capacitance of grain and grain boundaries $\left(C_{\mathrm{g}}, C_{\mathrm{gb}}\right)$ as a function of temperature are shown in figures $5 \mathrm{a}-\mathrm{c}$ (obtained from the Cole-Cole plots).

To understand the dielectric anomalies, dielectric measurements were made on this sample and are plotted in figure 6 . The dielectric constant almost remains constant in the temperature range $40-300^{\circ} \mathrm{C}$. On further increase in temperature, dielectric constant of the sample is found to increase very steeply. A small hump in the dielectric curve around $400^{\circ} \mathrm{C}$ is also observed. The dielectric data beyond $560^{\circ} \mathrm{C}$, in the paraelectric region did not fit to Curie-Weiss law. An alternative way of studying deviation from Curie-Weiss law, is to fit into diffuse phase transition (DPT) type, using the relation (Uchino and Nomura 1982)

$$
1 / \varepsilon=1 / \varepsilon_{\mathrm{m}}+\left[(T-\theta)^{2} /\left(2 \varepsilon_{\mathrm{m}} \delta^{2}\right)\right],
$$

where $\varepsilon_{\mathrm{m}}$ and $\delta$ are the maximum dielectric constant and deviation parameter of the sample, respectively. The value of the deviation constant so obtained is 35.4 .

Figure 7 shows the variation of pyroelectric coefficient with temperature. From the plot, transition temperature is found to be $570^{\circ} \mathrm{C}$. The spontaneous polarization calcu-

Table 1. Lattice parameters of BFT and LBFT compounds.

\begin{tabular}{|c|c|c|}
\hline Compound & BFT & LBFT \\
\hline Lattice parameters $(\AA)$ & $\begin{array}{l}a=5 \cdot 49 \pm 0 \cdot 01 \\
b=5 \cdot 50 \\
c=50 \cdot 18\end{array}$ & $\begin{array}{l}a=5 \cdot 45 \pm 0.01 \\
b=5 \cdot 76 \\
c=50 \cdot 75\end{array}$ \\
\hline $\begin{array}{l}\text { Orthorhombic } \\
\text { distortion }(b / a)\end{array}$ & $1 \cdot 006 \pm 0.001$ & $1 \cdot 057 \pm 0 \cdot 001$ \\
\hline $\begin{array}{l}\text { Interlayęr distance } \\
\quad(c / n) \AA\end{array}$ & $10 \cdot 036$ & $10 \cdot 158$ \\
\hline \multicolumn{3}{|l|}{ Density } \\
\hline X-ray $\left(\mathrm{g} / \mathrm{cm}^{3}\right)$ & $7 \cdot 94 \pm 0 \cdot 02$ & $7 \cdot 20 \pm 0 \cdot 02$ \\
\hline Exptl. $\left(\mathrm{g} / \mathrm{cm}^{3}\right)$ & $7 \cdot 54 \pm 0 \cdot 02$ & $7 \cdot 02 \pm 0 \cdot 02$ \\
\hline
\end{tabular}

lated from the area under the curve (figure 7) is plotted against $\left(T-T_{\mathrm{c}}\right)$ shown in the inset of figure 7.

The temperature dependence of electrical conductivity of ferroelectric is one of the important aspects in the present studies. As a rule, these materials should have ionic conductivity, which could be of intrinsic or extrinsic type (associated with defects). This is one of the typical characteristic features of ferroelectric materials. Small variation in the stoichiometry of the composition (mostly due to oxygen deficiency) leads to electron (hole) hopping conductivity. This type of conductivity plays an important role in the perovskite layers of oxygen-octahedra ferroelectrics. Thus, the conductivity evaluated for both the d.c. as well as a.c. is plotted against inverse of temperature and shown in figure 8 . From the plot, it is seen that with increasing temperature the conductivity of the sample increases. However, the increase is different in different temperature zones. The activation energy values are calculated from the slope of the graph and are given in table 2 .

From the lattice parameters (table 1) the $b / a$ value is found to be 1.057. By comparing the cell volumes and orthorhombic distortion of the present sample, it appears that $\mathrm{La}^{3+}$ incorporation lowers the lattice parameter ' $a$ ', whereas increases $b$ and $c$ parameters and the orthorhombic distortion, since the radius of $\mathrm{Bi}^{3+}$ is 0.96 , which is smaller than 1.016 of the $\mathrm{La}^{3+}$ ion. Interlayer distance $(c / n)$ (ratio of the $c$-parameter and the number of layers) is found to be $10 \cdot 15$, whereas for the BFT compound $c / n$ was found to be $10 \cdot 03$.

The density of the La-substituted compound is found to be more when compared to that of BFT compound. The experimental density of the sample is found to be $97.5 \%$ compared to that of theoretical density, which suggests that the porosity is very small. The microstructure has revealed that the compound consists of well-defined platelet structure. However, careful observations of the micro-

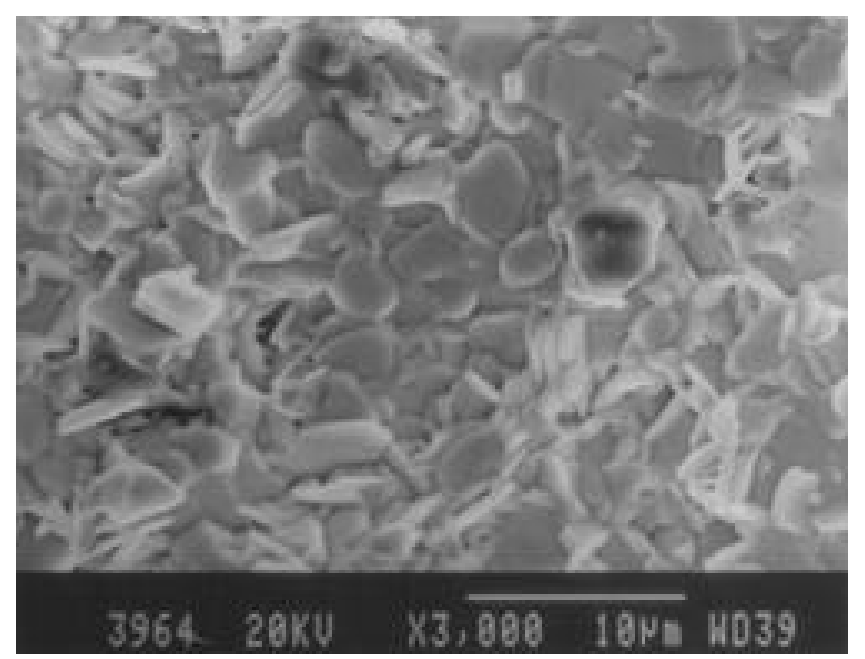

Figure 2. SEM picture of LBFT. 
graphs indicate presence of needle like grains also in the sample. In case of BFT, the micrograph showed needle like grains (Singh 1996). This indicates that $\mathrm{La}^{3+}$ to certain extent modifies the grain growth.

The combined $Z^{\prime \prime}$ and $M^{\prime \prime}$ plots drawn at different frequencies $\left(200-600^{\circ} \mathrm{C}\right)$ shows (figures $4 \mathrm{a}$ and b) the changes in both $Z^{\prime \prime}$ and $M^{\prime \prime}$ spectra with the increase in temperature and frequency. In all these plots at lower temperatures, the peak frequencies of $Z^{\prime \prime}$ and $M^{\prime \prime}$ are more apart and come closer at higher temperatures. Above study reveals, a non-Debye type behaviour and the dispersion in the data is due to the chemical heterogeneity, which is present in the material due to random distribution of cations in both $\mathrm{A}$ and $\mathrm{B}$ sites of $\mathrm{ABO}_{3}$ (Prasad et al 1998).

Due to slow diffusion of ions in the thermo mechanical process during solid state sintering of the constituent oxides, the resultant material would have microheterogeneities. These heterogeneities may be due to disorder resulting from random occupation of $\mathrm{La}^{3+}$ and $\mathrm{Bi}^{3+}$ in $\mathrm{A}$ sites and $\mathrm{Fe}^{3+}$ and $\mathrm{Ti}^{4+}$ in $\mathrm{B}$ sites of the $\mathrm{ABO}_{3}$ lattice. In
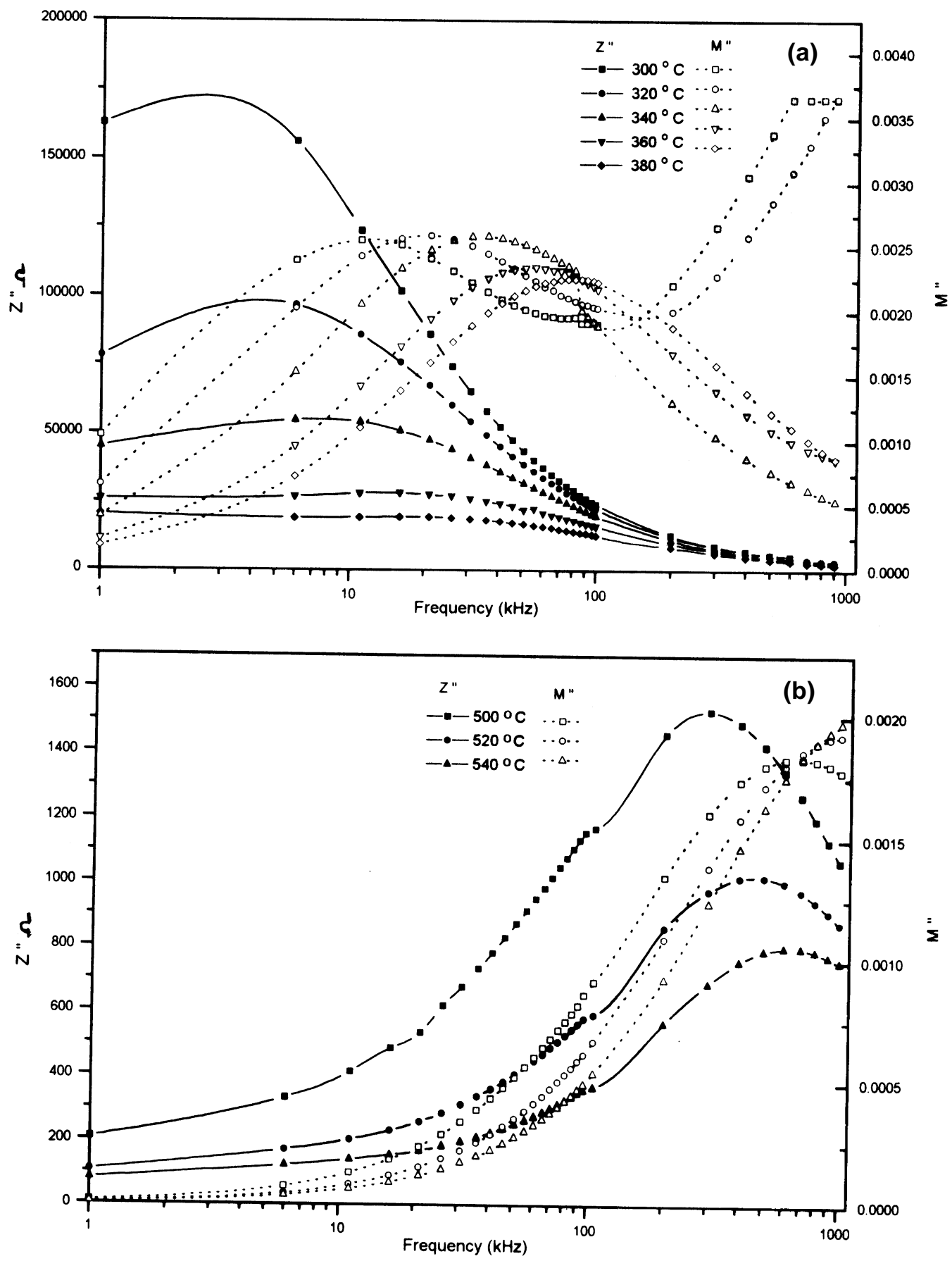

Figure 3. a-b. Variation of imaginary part of impedance $\left(Z^{\prime \prime}\right)$ and modulus $\left(M^{\prime \prime}\right)$ with frequency $(\mathrm{kHz})$ at different temperatures. 
this compound each unit cell contains five units of $\mathrm{ABO}_{3}$ structures. Each set of five units is separated by $\left(\mathrm{Bi}_{2} \mathrm{O}_{2}\right)^{2+}$ layers. Because of the random occupation of equivalent sites by different ions, there are fluctuations in structure. This may result in multiple relaxation phenomenon in these materials. This could be the reason for the observed broad peaks in $Z^{\prime \prime}$ vs frequency curves. The vacancy site present in the A site (Prasad et al 1998, 2000) may affect relaxation process in association with $\mathrm{La}^{3+}$ which occupies one of the $\mathrm{Bi}^{3+}$ sites in the perovskite layers.

Bismuth oxide compounds are expected to lose traces of oxygen during sintering at high temperature as per reaction (Kroger and Vink 1956):

$$
\mathrm{O}_{0} \rightarrow \frac{1}{2} \mathrm{O}_{2}+V_{0}^{\prime \prime}+2 e^{-}
$$

These defects affect impedance and capacitance in the formation of barrier layers at the grain-grain boundary interface. During cooling of the samples after sintering reoxidation takes place. This oxidation is limited to surface and grain boundaries only due to limited time. This results in difference between resistance of grain boundary and grain, giving rise to barriers (Chen Da Ren and Guo Yan Yi 1982).

At higher temperatures, it is observed that all ColeCole plots $\left(Z^{\prime \prime}\right.$ vs $\left.Z^{\prime}\right)$ are depicted on $Z^{\prime \prime}$ axis by a fixed $Z^{\prime}$ indicating thereby that there exists a constant resistance,
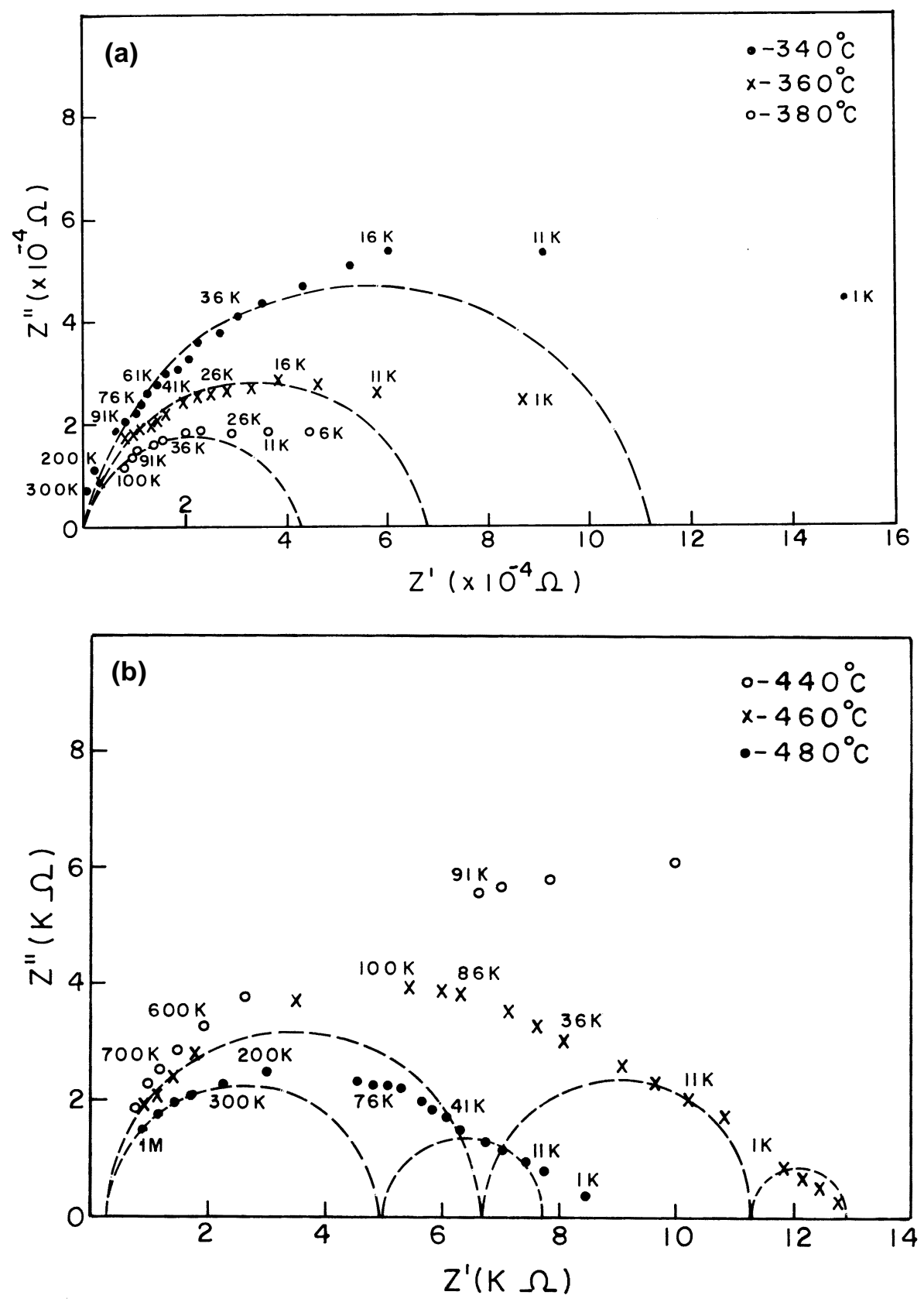

Figure 4. a-b. Cole-Cole plots. 
$r_{0}$. This resistance, $r_{0}$, is found to be independent of temperature and is added in series with three parallel RC circuits (figure 4). However, at higher temperatures as the resistance due to grain and grain boundary reduces and are probably comparable to the series resistance $\left(r_{0}\right)$ and hence $r_{0}$ is observable at higher temperatures.
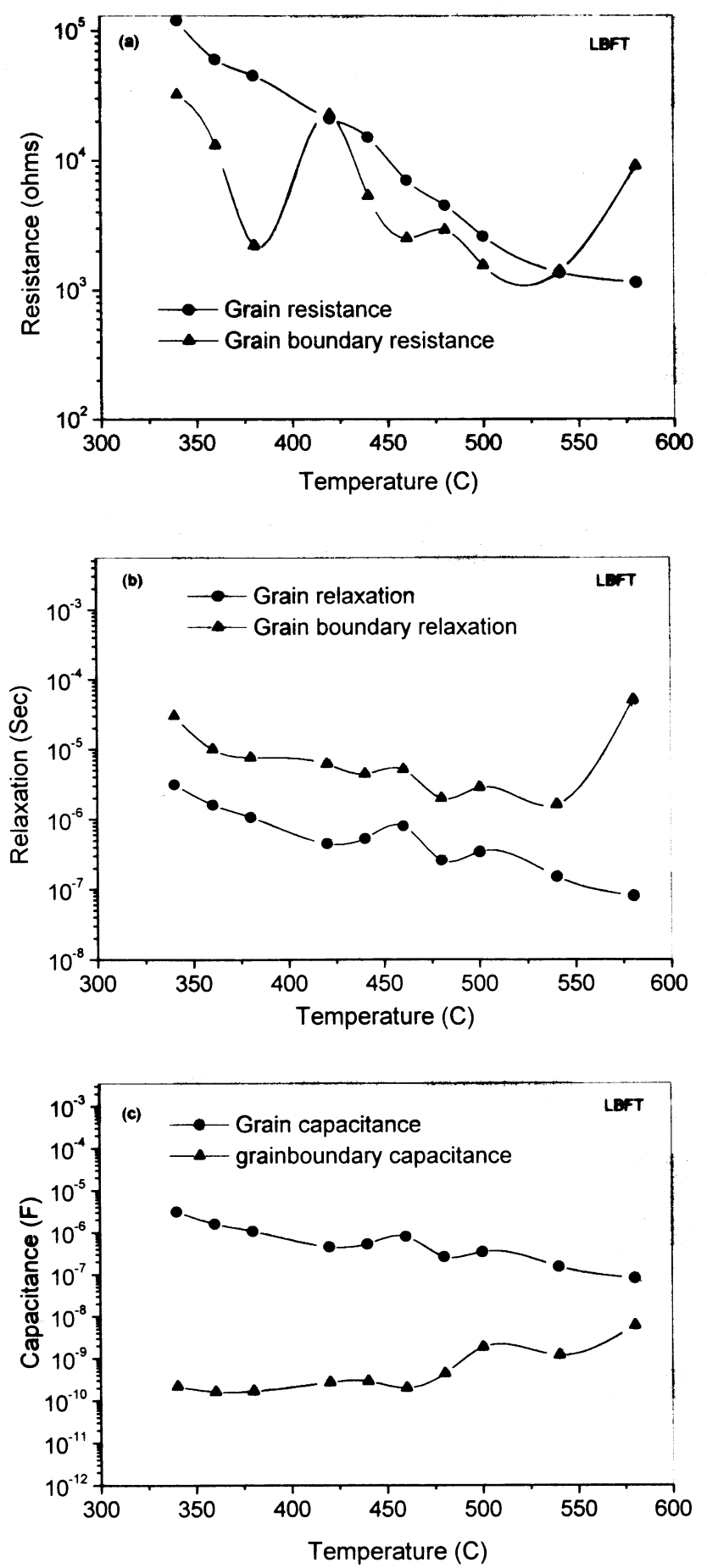

Figure 5. a-c. Variation of resistance, relaxation time and capacitance for grain and grain boundary with temperature.
The variation of $C_{\mathrm{gb}}$ with temperature shows smaller humps at the two transition temperatures observed in the dielectric measurements. A similar type of behaviour is also seen in case of $C_{\mathrm{g}}$. However, in case of $C_{\mathrm{gb}}$ beyond the second transition temperature, when the system enters the paraelectric state, the capacitance seems to increase with further increase of temperature. Correspondingly, grain boundary resistance is also observed to increase in this region. The grain boundary resistance is more than the grain resistance in the paraelectric region. This could be due to blocking of charges on either side of the grain boundary forming the potential barrier and hence blocking the passage of charge carriers. The effect of this is also seen in the form of increase in the activation energy (a.c. conduction) in the grain boundary at higher temperature region $\left(460-580^{\circ} \mathrm{C}\right)$. This indicates that the conduction in paraelectric region is basically through grains. The dielectric anomalies are seen in both $C_{\mathrm{g}}$ and $C_{\mathrm{gb}}$, which clearly indicate that the grain and grain boundary are ferroelectric. When $r_{\mathrm{g}}, r_{\mathrm{gb}}$ and $E_{\mathrm{g}}$ and $E_{\mathrm{gb}}$ are plotted as a function of inverse temperature, straight lines are obtained. Slope of the straight lines so obtained gives the resistance activation energy for grain $\left(E_{\mathrm{g}}\right)$ and grain boundaries $\left(E_{\mathrm{gb}}\right)$ and relaxation activation energy values of grain $\left(\varepsilon_{\mathrm{g}}\right)$ and grain boundary $\left(\varepsilon_{\mathrm{gb}}\right)$. The values obtained are summarized in table 3 .

The ferroelectric phase transitions of these materials are reported as displacive phase transitions. The phase transition temperature of BFT was reported to be $805^{\circ} \mathrm{C}$ (Deverin 1978; Singh 1996). However, the ferroelectric transition temperature of the present compound is considerably lower than that of BFT compound and is $550^{\circ} \mathrm{C}$ (figure 6a). The dielectric constant vs temperature graph shows broad maxima, which is the characteristic feature of diffuse phase transition. The value of Curie deviation factor is found to be 35.4 , which was calculated from the

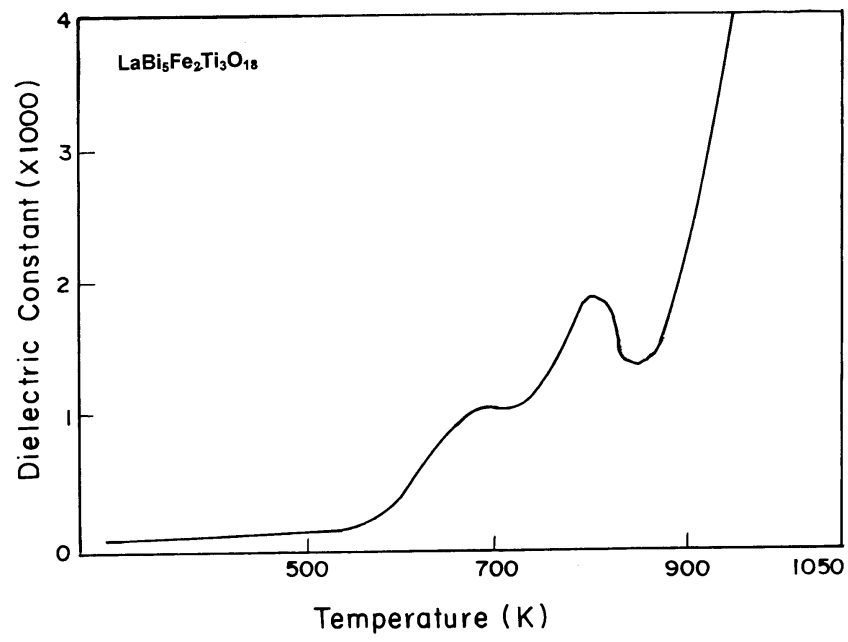

Figure 6. Variation of dielectric constant with temperature. 


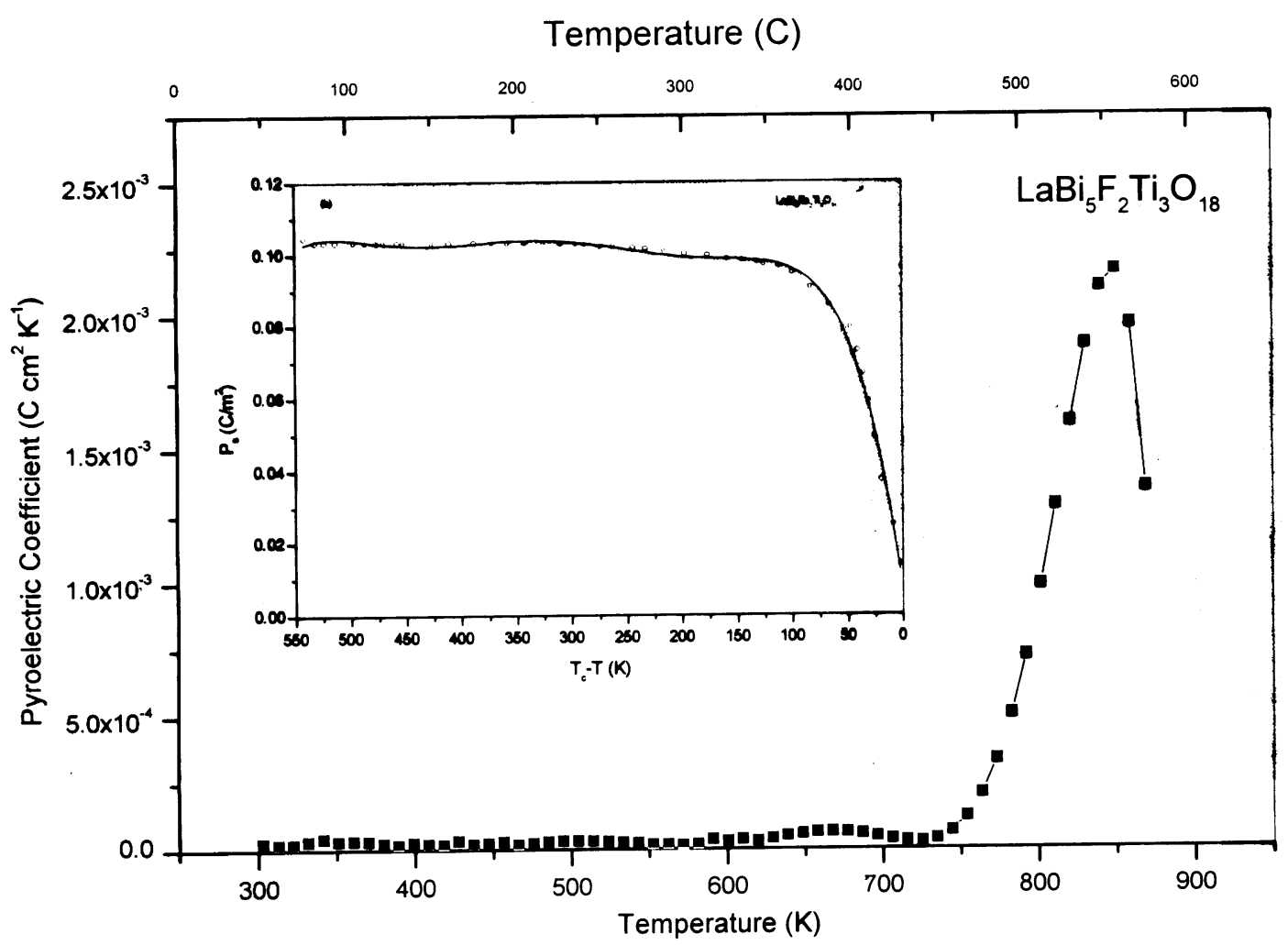

Figure 7. Variation of pyroelectric coefficient with temperature.

Table 2. A.c. and d.c. conduction activation energy values.

\begin{tabular}{lcccc}
\hline \multirow{2}{*}{$\begin{array}{l}\text { Temperature } \\
\text { range }\left({ }^{\circ} \mathrm{C}\right)\end{array}$} & $\begin{array}{c}\text { D.c. conductivity } \\
\text { activation energy, } \\
E(\mathrm{eV})\end{array}$ & \multicolumn{3}{c}{ A.c. conductivity activation energy (eV) } \\
\cline { 3 - 5 } & $0 \cdot 21$ & $11 \mathrm{kHz}$ & $51 \mathrm{kHz}$ & $100 \mathrm{kHz}$ \\
\hline $100-190$ & 1.22 & $0 \cdot 24$ & $0 \cdot 10$ & 0.04 \\
$230-450$ & 1.35 & 0.65 & 0.64 & 0.63 \\
$480-560$ & 0.89 & 0.89 & 0.89 \\
\hline
\end{tabular}

Table 3. Grain and grain boundary conduction activation energy values.

\begin{tabular}{lcccc}
\hline $\begin{array}{l}\text { Temperature } \\
\text { range } \\
(\mathrm{C})\end{array}$ & $\begin{array}{c}\text { Grain conduction } \\
\text { activation energy, } \\
E_{\mathrm{g}}(\mathrm{eV})\end{array}$ & $\begin{array}{c}\text { Grain boundary } \\
\text { conduction activation } \\
\text { energy, } E_{\mathrm{gb}}(\mathrm{eV})\end{array}$ & $\begin{array}{c}\text { Grain relaxation } \\
\text { activation energy, } \\
\varepsilon_{\mathrm{g}}(\mathrm{eV})\end{array}$ & $\begin{array}{c}\text { Grain boundary } \\
\text { relaxation activation } \\
\text { energy, } \varepsilon_{\mathrm{gb}}(\mathrm{eV})\end{array}$ \\
\hline $420-540$ & 0.91 & 1.02 & 0.60 & 0.53 \\
\hline
\end{tabular}

slope of $1 / \varepsilon$ vs $\left(T-T_{\mathrm{c}}\right)^{2}$ plot. Observing such broad transition is one of the prerequisite conditions for a material to be a relaxor ferroelectric (Newnham 1983; Cross 1987). The broad peak has been attributed to the random arrangement of ions $(\mathrm{La} / \mathrm{Bi}$ and $\mathrm{Fe} / \mathrm{Ti})$ in the structure leading to a microscopic heterogeneity in the composition due to the presence of four types of cations occupying A and B sites randomly in the lattice. The appearance of two semi circles in the Cole-Cole plots indicates that there are two relaxational mechanisms. These two relaxational mechanisms are due to grain and grain boundary. Figures $5 \mathrm{a}$ and $\mathrm{c}$ show that the resistance of grain and grain boundary are very close whereas the values of the capacitance for these two are quite different and tend to become close only at higher temperatures. This phenomena is clearly observed as $Z^{\prime \prime}$ and $M^{\prime \prime}$ peaks appear to merge at higher temperatures.

In the present sample, the substitution of $\mathrm{La}^{3+}$ in BFT has reduced considerably the transition temperature and hence the poling of the sample would be easier when 


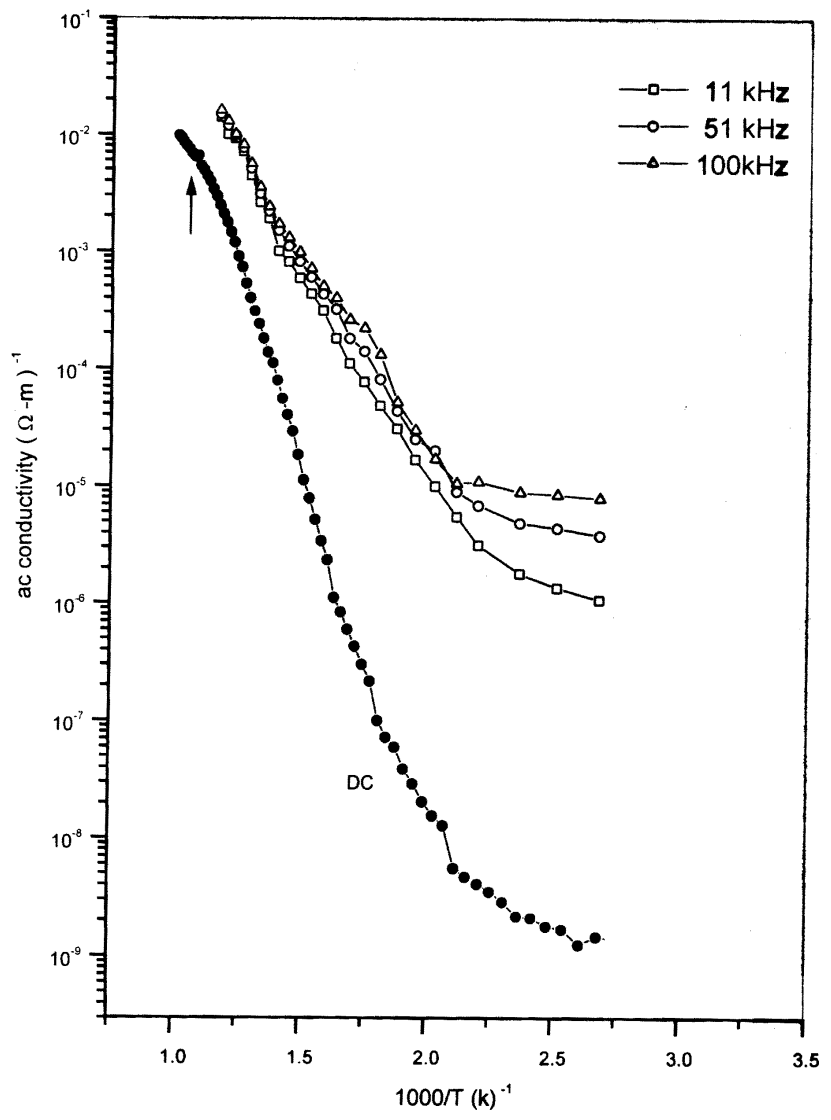

Figure 8. Variation of conductivity (a.c. and d.c.) with inverse of temperature $(K)$.

compared to BFT. As mentioned earlier, the pyroelectric current has been measured in order to ascertain the ferroelectric nature and also to measure the spontaneous polarization in this sample. The pyroelectric current clearly shows a peak around $570^{\circ} \mathrm{C}$, which is very close to the $T_{\mathrm{c}}$ observed in the dielectric measurements. The existence of pyroelectric current beyond $T_{\mathrm{c}}$ is also possible due to the permanent dipoles existing randomly in different regions beyond $T_{\mathrm{c}}$. As already mentioned, present sample has microheterogeneities in the composition and hence this also could be the reason for the observation of such a behaviour. From the pyroelectric current, the pyrocoefficient and the spontaneous polarization are evaluated and shown in figure 7 . From the plot, one could observe a change in pyroelectric coefficient and a small dip in the spontaneous polarization around $420^{\circ} \mathrm{C}$. This change corresponds to the hump observed around the same temperature in the dielectric data and hence may be thought of due to transition from one ferroelectric phase to another ferroelectric phase. However, this hump was attributed to change in magnetic ordering in BFT (Deverin 1978; Singh 1996). However, an order-disorder transition may also be responsible for such an observation. At this point it is not clear whether the transition is from one ferroelectric phase to another ferroelectric phase or it is only a small adjustment of the lattice because of the change in mag- netic ordering. The spontaneous polarization becomes zero at $560^{\circ} \mathrm{C}$, confirming that the present sample is ferroelectric below this temperature. The spontaneous polarization observed in this sample is around $10 \mu \mathrm{C} / \mathrm{cm}^{2}$, which is large when compared to $0.02 \mu \mathrm{C} / \mathrm{cm}^{2}$ for BFT (Deverin 1978). From the $P_{\mathrm{s}}$ vs $\left(T-T_{\mathrm{c}}\right)$ graph, it is seen that the $P_{\mathrm{s}}$ value decreases continuously but sharply near the transition temperature, which indicates that the transition is of second order. From the $\mathrm{P}_{\mathrm{s}}$ value, obtained from the pyroelectric measurements, the dipole moment per unit cell is found to be $1.76 \times 10^{-26} \mathrm{C} \mathrm{cm}$.

The dielectric response of these materials with temperature shows spontaneous polarization due to the permanent dipoles present in the system. Their presence can be seen from the d.c. conductivity data and from the changes in slopes at low temperatures $\left(\sim 320^{\circ} \mathrm{C}\right)$. At the same time, change in activation energy below and above the transition temperature region in between $230-450^{\circ} \mathrm{C}$ and 480 $560^{\circ} \mathrm{C}$ confirms the transition temperature of the sample.

A change in activation energy around $500^{\circ} \mathrm{C}$ is due to the lattice adjustment that takes place at the phase transition from ferroelectric to paraelectric region. Slope change and hence change in activation energy observed around $400^{\circ} \mathrm{C}$ may be attributed to the readjustment of lattice between two ferroelectric regions, viz. FE I (at $430^{\circ} \mathrm{C}$ ) and FE II (at $530^{\circ} \mathrm{C}$ ). This change may be of order disorder type, which results in change in conduction mechanism and hence in activation energy.

A knee point (slope change) in d.c. conductivity data (figure 8) is attributed to the transition temperature. This means the rearrangement of the structure in the phase transition region or the appearance (disappearance) of the spontaneous polarization is accompanied with the change in activation energy values. This point is indicated in figure 8 .

A.c. conductivity $\left(\sigma_{\text {a.c. }}\right)$ of the present sample was calculated at different frequencies and temperatures using $Y^{\prime}$ values (figure 8 ). The activation energies at different frequencies and at three temperature zones are given in table 2. It is apparent that in low temperature regime the a.c. conductivity depends significantly on the frequency as usually observed in this type of materials (Singh 1996; James 1997). At lower temperatures and higher frequencies, it is observed to be independent of temperature. However, with the increase in temperature, the dielectric relaxation takes place and the dependency of conductivity on frequency gets reduced. It is noted that both the conductivity curves $\left(\sigma_{\text {a.c. }}\right.$ and $\left.\sigma_{\text {d.c. }}\right)$ are found to merge at higher temperatures and at these temperatures the onset of intrinsic conductivity takes place.

\section{Conclusions}

In view of the above discussions the following conclusions are arrived at: 
(I) Five layered La substituted BFT $\left(\mathrm{LaBi}_{5} \mathrm{Fe}_{2} \mathrm{Ti}_{3} \mathrm{O}_{18}\right)$ compound is found to form a single-phase material. La substituted in BFT increases the density, decreases the porosity and enhances the grain growth.

(II) From the impedance spectroscopic studies, the samples showed relaxational effects and the relaxations are of non-Debye type. The relaxational frequencies shifted to higher frequencies with the increase of temperature.

(III) Incorporation of La in BFT decreases the ferroelectric transition temperature by about $250^{\circ} \mathrm{C}$ i.e. from $805^{\circ} \mathrm{C}$ to $560^{\circ} \mathrm{C}$. The dielectric anomaly is of diffuse phase transition type and the deviation parameter is evaluated as 35.4. Pyroelectric and spontaneous polarization studies confirmed the ferroelectric nature of the sample. The ferroelectric transition appears to be a second order transition.

\section{Acknowledgement}

One of the authors (NVP) thanks CSIR, New Delhi, for the award of a Senior Research Fellowship.

\section{References}

Auruvillius B 1949 Arki Kemi 1 463, 499

Auruvillius B 1950 Arki Kemi 2519

Chen Da Ren and Guo Yan Yi 1982 Electronic Elements and Materials 125

Cole K S and Cole R H 1941 J. Chem. Phys. 9341
Cross L E 1987 Ferroelectrics 76241

Deverin J A 1978 Ferroelectrics 199

Fregoso O A 1997 J. Appl. Phys. 181

Ismailzade I H, Yakupov R G and Melik-Shanazarova T A 1971 Phys. Status Solidi 6 K85

James A R 1997 Synthesis, impedance spectroscopy and magnetic studies on some bismuth layer structured materials, Ph.D. Thesis, Osmania University, Hyderabad

James A R, Kumar G S, Suryanarayana S V and Bhimasankaram T 1998 Ferroelectrics 21611

Kroger F A and Vink H J 1956 Solid State Phys. 3307

Macdonald J R 1987 Impedance spectroscopy (NY: Wiley)

Mahesh Kumar M 1998 Electrical, dielectric and magnetoelectric studies in $\mathrm{BiFeO}_{3}-\mathrm{BaTiO}_{3}$ solid solutions, Ph.D. Thesis, Osmania University, Hyderabad

Newnham R E 1983 J. Mater. Edu. 594

Prasad N V and Kumar G S 2000 J. Mag. Mater. 213349

Prasad N V, Prasad G, Bhimasankaram T, Suryanarayana S V and Kumar G S 1998 Mod. Phys. Letts B12 371

Prasad N V, Mahendra Kumar, Prasad G, Bhimasankaram T, Suryanarayana S V and Kumar G S 2000 Bull. Mater. Sci. 23 483

Singh R S 1996 Structure-property correlations in some magnetically ordered Auruvillis phases, Ph.D. Thesis, Osmania University, Hyderabad

Subba Rao E C 1962 J. Phys. Chem. Solids 23665

Takenaka T and Sakata K 1980 Jap. J. Appl. Phys. 1931

Takenaka T and Sakata K 1983 Jap. J. Appl. Phys. 2253

Takenaka T and Sakata K 1984 J. Appl. Phys. 551092

Uchino K and Nomura S 1982 Ferroelectrics Lett. Sect. 44 55

Von Hipple R 1954 Dielectrics and waves (NY: John Wiley and Sons) 